\title{
PESCA EM TABLADOS E EDUCAÇÃO AMBIENTAL: ESTUDO COM PESCADORES DO RESERVATÓRIO DA USINA DE NOVA PONTE-MG
}

\author{
Edna Maria Soares Rodrigues ${ }^{1}$ \\ Leonice Domingos dos Santos Cintra Lima ${ }^{2}$ \\ Luiz Sérgio Vanzela ${ }^{3}$
}

Resumo: A atividade pesqueira em tablados é comum na região de Nova Ponte, MG. A ação do homem no meio ambiente pode ocasionar impactos com consequências irreversíveis, se não forem observadas medidas de preservação. O uso de tablados produz resíduos oriundos das cevas ${ }^{4}$, aumentando a poluição das águas. Este trabalho objetiva conhecer o perfil dos pescadores e propor alternativas para sua conscientização. Utilizou-se de pesquisa de campo, com questionários para conhecimento da realidade. A pesquisa aponta a necessidade de uma proposta de educação ambiental, objetivando sensibilizar os pescadores sobre o tema. Para tal, foi elaborado folder contendo informações sobre a pesca, objetivando promover a sua conscientização.

Palavras-chave: Atividade pesqueira. Educação ambiental. Poluição das águas.

\section{PLATFORMS FISHING AND ENVIRONMENTAL EDUCATION: STUDY WITH FISHERS OF NOVA PONTE LAKE- MG (BRAZIL)}

Abstract: The fishing activity on the floating platforms is common in the region of Nova Ponte, MG (Brazil). The man's action in the environment can cause impacts with irreversible consequences if the conservation measures are not observed. The use of floating platforms produces waste from the cevas ${ }^{5}$, increasing water pollution. This study aims to understand the profile of the fishers and propose alternatives for their awareness. They used field research, with questionnaires in order to know the reality. The research points to the need for a proposed environmental education, aiming awareness among fishermen on the subject. Folder was prepared containing information about fishing, aiming to promote their awareness.

Keywords: Fishing activity. Environmental education. Water pollution.

\footnotetext{
${ }^{1}$ Mestre em Ciências Ambientais pela Universidade Camilo Castelo Branco (UNICASTELO). ednataina@yahoo.com.br

${ }^{2}$ Doutora em Serviço Social pela Faculdade de História, Direito e Serviço Social pela Universidade Estadual Paulista (UNESP/Franca/SP). Professora titular, curso de graduação em Serviço Social e do programa Stricto Sensu em Ciências Ambientais da Universidade Camilo Castelo Branco (UNICASTELO), Fernandópolis, São Paulo, Brasil. lecaclima@yahoo.com.br

${ }^{3}$ Doutor em Agronomia pela Universidade Estadual Paulista (UNESP). Coordenador de curso e professor titular, professor do curso de graduação em agronomia e do programa stricto sensu em ciências ambientais da Universidade Camilo Castelo Branco (UNICASTELO), Fernandópolis, São Paulo, Brasil.

lsvanzela@yahoo.com.br

${ }^{4}$ A ceva é usada pelos pescadores da pesca esportiva para atrair os peixes até a isca. Geralmente empregada na pesca sob girais, barrancos ou barcos, a variedade de iscas é imensa para garantir perfeito desempenho na pesca. Disponível em: <http://revistapescaecompanhia.com.br/fique-por-dentro/dicas-de-ceva〉. Acesso em: 02 fev. 2015.

${ }^{5}$ It is a fishing' strategy that uses specific bait to attract fish. There is no translation for the entry.
} 


\section{PLATAFORMAS DE PESCA Y EDUCACIÓN AMBIENTAL: ESTUDIO CON PESCADORES DEL EMBALSE DE LA PLANTA PONTE NOVA-MG}

Resumen: La actividad pesquera en las plataformas es común en la región de Ponte Nova, MG. La acción del hombre sobre el medio ambiente puede resultar en impactos con consecuencias irreversibles, si no son las medidas de conservación observadas. El uso de plataformas produce residuos de las cevas ${ }^{6}$, el aumento de la contaminación del agua. Este estudio tiene como objetivo conocer el perfil de los pescadores y proponer alternativas para su conciencia. Se utilizó la investigación de campo, con cuestionarios para el conocimiento de la realidad. La investigación demuestra la necesidad de una propuesta de educación ambiental, con el objetivo de sensibilizar a los pescadores sobre el tema. Para ello, se diseñó carpeta que contiene información sobre la pesca, con el objetivo de promover su conocimiento.

Palabras-llave: Pesca. Educación ambiental. Contaminación hídrica.

\section{Introdução}

No Brasil, a pesca, além de representar uma fonte de renda para um número significativo de famílias, também figura como uma atividade de lazer de baixo custo, tendo em vista o volume de recursos hídricos de algumas regiões. A construção de reservatórios de água, necessários às usinas hidrelétricas, potencializou, na região que liga os estados de Minas Gerais, São Paulo e Goiás, a pesca em suas mais variadas modalidades: esportiva, de subsistência e predatória.

A área delimitada para esta pesquisa foi o lago da Usina Hidrelétrica de Nova Ponte, MG (Brasil), na região situada entre os municípios de Nova Ponte e Santa Juliana, ambos em Minas Gerais, nas proximidades da ponte sob o rio Araguari, que faz divisa com os dois municípios.

A construção da Usina Hidrelétrica de Nova Ponte teve seu início em 1987, e o início de operação se deu em 1994. O comprimento da barragem é de $1.620 \mathrm{~m}$. A altura máxima da barragem é de $142 \mathrm{~m}$. O volume do reservatório é de $12.792 \mathrm{hm}^{3}$ e a usina possui três unidades geradoras, com potência instalada de 510 MW (CEMIG, 2005).

Na região do reservatório há uma considerável incidência de atividade pesqueira, praticada por proprietários de ranchos ali construídos. Aliada à presença dos ranchos, registrase quantidade expressiva de tablados flutuantes utilizados por pescadores, que são estruturas compostas de plataforma e parapeitos de madeira sobre flutuadores, com dimensões máximas de $15 \mathrm{~m}^{2}$ (MATO GROSSO DO SUL, 2012).

O impacto de sua presença na região interfere nas condições ambientais, conforme é apresentado por Silva (2009, p. 29): "Um reservatório impõe significativas mudanças na escala temporal e espacial dos fenômenos que ocorrem num curso d'água. Consequentemente, isso altera sensivelmente os processos físicos, químicos e biológicos dos ecossistemas presentes na região".

Vasconcelos (2012), em sua tese de doutorado, caracterizou as alterações espaciais e temporais das condições e padrões de qualidade da água do Rio Uberabinha, que representa um dos principais recursos hídricos da região, responsável pelo fornecimento de água para uma população de mais de 600 mil habitantes da cidade de Uberlândia (MG).

\footnotetext{
${ }^{6}$ Estrategia de pesca utilizada para atraer a un mayor volumen de pescado. No hay traducción para la entrada.
} 
Entre os objetivos do trabalho de Vasconcelos (2012), vale destacar a contribuição para que a distribuição da água seja mantida para o futuro e a avaliação da qualidade da água, utilizando-se análises químicas e microbiológicas e teste de micronúcleos em peixes.

O pescador, ao servir-se do tablado enquanto realiza a atividade pesqueira, além de produzir resíduos domésticos comuns, habitualmente, prepara a ceva, recorrendo a produtos de origem animal e vegetal, tais como: torresmo prensado, mortadela, milho, soja, ração etc.

A Lei n. 9.605, de 12 de fevereiro de 1998, em seu capítulo V - Dos Crimes Contra o Meio Ambiente - seção III - Da Poluição e outros crimes ambientais, em seu artigo 54 parágrafo, $2^{\circ}$ - inciso $\mathrm{V}$, prevê: "Se o crime ocorrer por lançamento de resíduos sólidos, líquidos ou gasosos, ou detritos, óleos ou substâncias oleosas, em desacordo com as exigências estabelecidas em leis ou regulamentos: Pena - reclusão, de um a cinco anos. (BRASIL, 1998, s/p).

Partindo do pressuposto de que os tablados são espaços nos quais são produzidos tanto resíduos orgânicos como resíduos secos, e de que estes, quando descartados nos corpos d'água, contribuem para o aumento da poluição das águas dos rios e represas, é certo afirmar que a presença do homem interfere no meio ambiente.

A atividade pesqueira é regulamentada pela Lei Federal n. 11.959, de 29 de junho de 2009, que dispõe sobre a Política Nacional de Desenvolvimento Sustentável da aquicultura e tem como objetivo:

Promover o desenvolvimento sustentável da pesca e da aquicultura como fonte de alimentação, emprego, renda e lazer, garantindo-se o uso sustentável dos recursos pesqueiros, bem como a otimização dos benefícios econômicos decorrentes em harmonia com a preservação e a conservação do meio ambiente e da biodiversidade (BRASIL, 2009, s/p).

Prevê, ainda, as restrições no período da Piracema ${ }^{7}$, conhecido também como período de defeso, segundo o artigo $2^{\circ}$, inciso XIX: "a paralisação temporária da pesca para a preservação da espécie, tendo como motivação a reprodução [...].” (BRASIL, 2009, s/p).

Ainda, a mesma lei, na seção II - Da atividade Pesqueira, em seu artigo $5^{\circ}$, inciso I, prevê:

[...] a atividade pesqueira somente poderá ser realizada mediante prévio ato autorizativo emitido pela autoridade competente, asseguradas: “[...] a proteção dos ecossistemas e a manutenção do equilíbrio ecológico, observados os princípios de preservação da biodiversidade e o uso sustentável dos recursos naturais [...]" (BRASIL, 2009, s/p).

O uso de tablados como opção de pesca e lazer, além de oferecer vantagens econômicas, praticidade e conforto, representa uma alternativa a mais para o pescador, que se vê impedido de construir o rancho a menos de 100 metros da margem do lago, conforme dispõe a Resolução do Conselho Nacional de Meio Ambiente (CONAMA) n. 302/02, de 20 de março de $2002^{8}$ (CONAMA, 2002).

Considerando, nesse contexto, que a sustentabilidade da atividade de lazer e pesca em tablados depende dos próprios usuários, este trabalho teve como objetivo conhecer o perfil

\footnotetext{
${ }^{7}$ Piracema (região do Triângulo Mineiro): período compreendido entre os meses de novembro e fevereiro na região pesquisada, quando ocorre o processo de desova ou procriação dos peixes, e a pesca possui restrições regulamentadas por lei. A desobediência a essa legislação pode levar a penalidades que variam da apreensão do material de pesca e do pescado, aplicação de multa até a detenção do infrator (MINAS GERAIS, 2011).

${ }^{3}$ Resolução do Conselho Nacional de Meio Ambiente n. 302/02, de 20 de março de 2002 (CONAMA, 2002).
} 
dos pescadores e analisar o nível de conscientização quanto à preservação dos recursos naturais e propor alternativas para a mudança de comportamento dessa categoria.

Para Carvalho (2011, p. 183):

A orientação comportamental é, sobretudo, aquela que foi incorporada por uma psicologia da consciência que aposta em um sujeito racional. Isto significa [...] considerar o comportamento [...] capaz de expressar as motivações dos indivíduos e acreditar que é possível submeter à vontade deles e produzir transformações, dessas motivações mediante um processo racional, o qual se passa no plano do esclarecimento, do acesso a informações coerentes e da tomada de decisões racionais, baseadas em uma relação de custo-benefício para o sujeito.

\section{Material e Métodos}

Para a definição do universo da pesquisa, foram delimitados 08 (oito) pontos ao longo das margens do lago ${ }^{9}$, na área onde se concentra a maior quantidade de tablados, para a aplicação dos questionários, registro e observação do cenário visualizado naquele ecossistema, conforme evidenciado na figura 1.

Figura 1 - Delimitação da área de pesquisa.

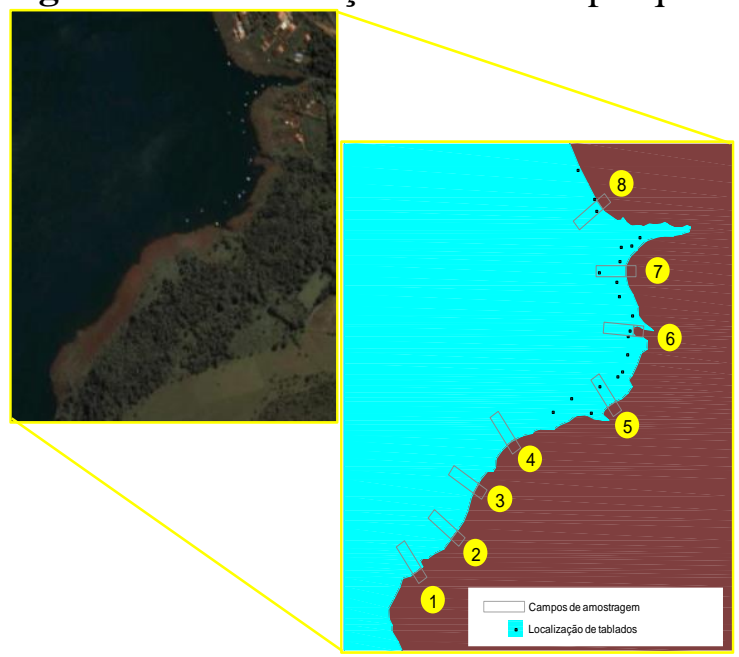

Fonte: Vanzela, 2013.

Os sujeitos da pesquisa foram escolhidos aleatoriamente entre os que utilizam tablados instalados no espaço delimitado como área da pesquisa. Não teve relevância, na definição dos indivíduos, a modalidade da atividade pesqueira desenvolvida (pesca esportiva ou pesca profissional/sustento familiar). O quantitativo de participantes se deu por representatividade social, por se entender que esta pesquisa não está em busca de generalizações, assim, "não tem muito sentido falar de amostragem, pois não se procura uma representatividade estatística e sim uma 'representatividade social' [...]" (GUERRA, 2006, p. 40).

Para aproximação e conhecimento da realidade, com vistas ao objetivo proposto, utilizou-se como instrumento da pesquisa um questionário de caráter qualitativo, aplicado aos pescadores que, voluntariamente, após ciência, esclarecimento e assinatura do Termo de Consentimento Livre e Esclarecido (TCLE), se interessaram em participar do estudo. A

\footnotetext{
${ }^{4}$ Lago: Denominação utilizada na região para caracterizar reservatórios de usinas hidrelétricas tendo em vista o volume de água desses reservatórios.
} 
estrutura qualitativa do instrumento da pesquisa teve como objetivo conhecer o posicionamento do pescador, que traduz os aspectos de atitudes, opiniões, valores e conhecimento de estatutos legais sobre impactos ambientais, pois, conforme preconiza Minayo (2001, p. 21):

A pesquisa qualitativa responde a questões muito particulares [...] ela trabalha com o universo de significados, motivos, aspirações, crenças, valores, atitudes, o que corresponde ao espaço mais profundo das relações, dos processos e dos fenômenos que não podem ser reduzidos à operacionalidade de variáreis.

O contato com os pescadores deu-se no próprio lago, com uso de embarcação para facilitar o acesso até os tablados.

A realização da pesquisa foi validada pelo Comitê de Ética em Pesquisa (CEP) da Universidade Camilo Castelo Branco - UNICASTELO, por meio do Parecer Consubstanciado-Aprovado, emitido em 11 de março de 2014, sob o CAAE: 22148114.4.0000.5494.

\subsection{O universo da pesquisa}

A pesquisa foi conduzida no município de Santa Juliana - MG, que faz divisa com o município de Nova Ponte - MG, no Lago da Usina Hidrelétrica de mesmo nome, nas coordenadas $19^{\circ} 16 ' 59,24^{\prime \prime}$ Sul e 47³7'22,70" Oeste.

Durante as visitas realizadas ao lago, encontraram-se quantidades expressivas de resíduos nas margens do reservatório, compostas, principalmente, por tambores de aço abandonados, restos de tablados compostos por ferragens, pedaços de madeira, restos de mobília e materiais de construção, plásticos, garrafas PET, latinhas de alumínio, embalagens de plástico, pilhas, redes de pesca, confirmando a agressão ao meio ambiente e o desconhecimento ou desinteresse dos pescadores e da população usuária do lago pela preservação da biota.

A poluição ambiental revela o desconhecimento ou pouca conscientização dos pescadores e usuários do local e demonstra a pouca disposição em adotar medidas mitigadoras que evitem a degradação do meio ambiente, como evidenciado na figura 2.

As visitas ao Reservatório (cuja permanência, em todas as ocasiões, foi superior a 4 horas consecutivas) revelaram a incipiência de fiscalização pelos órgãos ambientais, fato mencionado pelos pescadores nas respostas ao questionário da pesquisa.

Figura 2 - Tambores e restos de tablados às margens do lago.

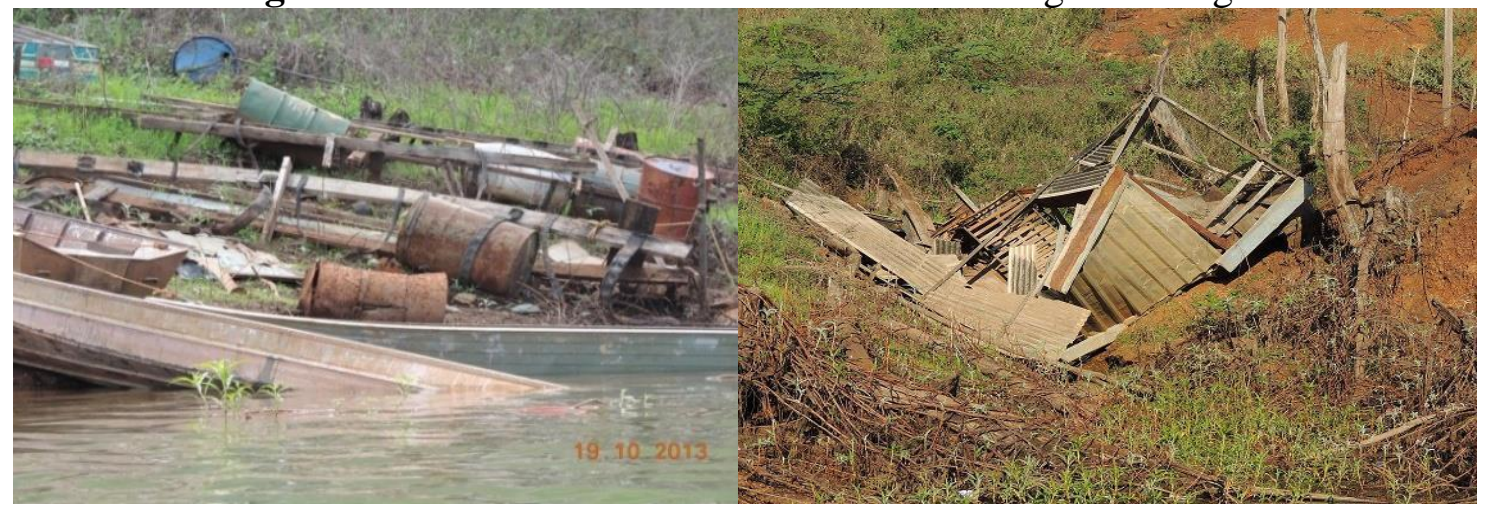

Fonte: a autora, 2013. 
A realidade local registrada revela o baixo nível de conscientização e consciência ambiental dos pescadores e usuários do Reservatório da Usina de Nova Ponte - MG, entendendo conscientização a partir do conceito de Freire (2001 apud DAMO; MOURA; CRUZ, 2011, s/p. ) como:

O processo de formação de uma consciência crítica em relação aos fenômenos da realidade objetiva. [...] a transformação social passa pelo desenvolvimento coletivo de uma consciência crítica sobre o real. É importante que neste processo de conscientização os sujeitos se reconheçam no mundo e com o mundo, havendo a possibilidade de que, na transformação do mundo, transformem a si mesmos. Nesse sentido, a formação de uma consciência crítica coletiva é a condição fundamental para a transformação de uma coletividade.

E, entendendo educação ambiental a partir do conceito de Mousinho (2003, p. 158) como:

Um processo em que se busca despertar a preocupação individual e coletiva para a questão ambiental [...] contribuindo para o desenvolvimento de uma consciência crítica [...] procurando trabalhar não apenas a mudança cultural, mas também a transformação social, assumindo a crise ambiental como uma questão ética e política.

Buscaram-se, nos estudos de Tundisi (2009), as referências fundamentais para a importância da água como elemento imprescindível à vida na terra. Segundo o autor:

Qualquer forma de vida depende da água para sua sobrevivência e/ou para seu desenvolvimento [...]. Onde não há água não há vida [...] A água doce é, portanto, essencial à sustentação da vida [...]. Embora dependam da água para a sobrevivência e para o desenvolvimento econômico, as sociedades humanas poluem e degradam este recurso [...] (TUNDISI, 2009, p. 1).

A argumentação do autor sobre o valor da água para a sobrevivência de qualquer ser vivo remete a uma realidade contundente e séria sobre o comportamento do homem frente aos recursos naturais. Ao apontar que, apesar de reconhecerem o valor da água, as sociedades humanas continuam degradando e poluindo esse recurso, indispensável à sobrevivência de qualquer espécie de vida, o autor chama a atenção para a gravidade do problema e a necessidade de mudanças de comportamento do ser humano.

\section{Apresentação e análise dos resultados}

\subsection{Perfil dos participantes da pesquisa}

A pesquisa permitiu a elaboração do perfil dos pescadores usuários de tablados do Reservatório da Usina Hidrelétrica de Nova Ponte - MG. Dessa forma, pode-se definir que, em sua maioria, esses pescadores são do sexo masculino, o que representa $75 \%$ dos participantes.

A faixa etária predominante está acima de 30 anos (70\%). Esse percentual evidencia que o grupo pertencente à faixa etária mais jovem não tem muito interesse pela atividade pesqueira, tanto quanto a faixa etária acima dos 30 anos.

O nível de escolaridade no Ensino Médio é de 50\%, seguido do Ensino Fundamental, com o percentual de $30 \%$. Somente $20 \%$ cursaram o ensino superior.

A pesquisa aponta que, na região pesquisada quanto a essa atividade pesqueira, não é expressiva a presença de população com nível de escolaridade mais elevado, ou seja, quanto 
maior nível de instrução o indivíduo possui, menor é o interesse pela prática de atividade pesqueira em tablados.

Referem serem proprietários de tablados $45 \%$, enquanto $55 \%$ dos entrevistados se apresentam como visitantes convidados ou locadores.

Nenhum dos participantes assegurou ser pescador profissional ou fazer uso do tablado com a finalidade de sustento familiar ou como fonte complementar de renda, e todos referem utilizar o tablado para a pesca esportiva ou lazer.

Todos os entrevistados frequentam os tablados em grupos, normalmente compostos de três a cinco pessoas.

Foi realizada uma visita técnica no período da Piracema (fevereiro de 2014), observando-se que alguns pescadores estavam praticando a atividade normalmente, como também preparando os materiais a serem utilizados como cevas para atrair os peixes.

Portanto, mesmo durante o período em que há restrições à pesca, alguns pescadores insistiam em não observar a legislação que regulamenta o período de defeso, evidenciando, mais uma vez, a necessidade de intervenções educativas junto a esse público, objetivando a conservação dos recursos hídricos na região de estudo.

\subsection{Análise dos resultados das respostas ao questionário - questões abertas}

1 - O que você conhece sobre a legislação que controla (disciplina) a piracema?

A grande maioria (90\%) conhece a legislação que regulamenta a piracema e reconhece sua importância para a reprodução dos peixes. Apenas 5\% afirmaram saber que o período da piracema é de novembro a fevereiro e 5\% afirmaram que ela é importante para o aumento do peixe.

2 - O que você acha do período da piracema?

Quanto à opinião do pescador sobre a importância do período da piracema, grande parte dos entrevistados $(65 \%)$ a considera importante para a preservação das espécies; $15 \%$ apontaram a fiscalização como precária e a falta de esclarecimentos dos pescadores e $5 \%$ a consideram importante, mas precisa ser mais eficiente para surtir efeito; $10 \%$ asseguram ser muito importante e 5\% afirmam que é preciso respeitar a lei porque senão não tem o que pescar.

Essas respostas mostram que o pescador tem consciência da importância das restrições impostas pela legislação quanto à pesca no período da piracema e reconhece que é importante observá-las para garantir a reprodução dos peixes.

3 - Quais as razões da diminuição da quantidade de peixes?

Quanto às razões para a diminuição dos peixes, $30 \%$ apontam a falta de fiscalização, $20 \%$ a poluição das águas, $15 \%$ a falta de conscientização dos pescadores, $5 \%$ o excesso de pescadores, $10 \%$ o excesso de represas, $10 \%$ o peixe predador (piranha e tucunaré) e $5 \%$ apontam as condições climáticas (falta de chuva), assim como 5\% apontam o pescador profissional como responsável pela diminuição de peixes no local.

Novamente, são apontados pelos pescadores os problemas já mencionados em outros itens do questionário, como a falta de fiscalização por parte das autoridades ambientais como fator negativo para a conservação das espécies de peixes.

4-O que você usa como ceva? 
O uso da ceva para atrair os peixes para as proximidades dos tablados e facilitar sua captura foi confirmado por quase todos os pescadores entrevistados (95\%), reiterando a hipótese enunciada no início do projeto da pesquisa.

\section{5 - Onde é depositado o lixo produzido no tablado?}

Quanto à destinação dos resíduos produzidos no tablado, $40 \%$ afirmam que são depositados em uma caçamba, longe das margens do lago, $45 \%$ afirmam que os conduzem à cidade de origem quando deixam o tablado e $15 \%$ disseram que os acondicionam em sacos para lixo, mas não informaram o destino final desses resíduos, o que pode sinalizar para a possibilidade de os resíduos serem atirados diretamente nas águas do reservatório, uma hipótese levantada no projeto inicial desta pesquisa.

\section{6 - Quais os outros fatores que afetam a vida dos peixes?}

Quanto a outros fatores que afetam a vida dos peixes, apontados pelos entrevistados, foram citados: agrotóxicos utilizados na lavoura, alimentos descartados no lago, desrespeito à legislação, falta de apoio dos órgãos governamentais quanto ao cumprimento da legislação, falta de fiscalização, a presença de peixes predadores também conhecidos como peixes exóticos, como o tucunaré e a piranha, o pescador profissional, a poluição das águas e a poluição sonora registrada naquela área do lago.

Novamente, a ação dos órgãos ambientais é cobrada como agente fiscalizador, o que pode contribuir para que a legislação seja respeitada e, como consequência, o período da piracema seja observado e a procriação das espécies não seja prejudicada.

Com referência à preservação da vida dos peixes, a pesquisa registra que $70 \%$ dos entrevistados apresentaram respostas associadas à presença do homem na região (aumento da poluição das águas, excesso de resíduos nas encostas e margens, aumento do número de pescadores etc.) - o que mostra a falta da ação efetiva do Estado como fiscalizador -, e 10\% dos participantes fizeram referência à presença de predadores naturais na região (outras espécies de peixes não nativos da região, denominados por especialistas como peixes exóticos, como tucunaré e piranha).

Apenas 5\% dos entrevistados associaram o desaparecimento dos peixes a problemas climáticos, como longos períodos de estiagem e diminuição do volume de água no reservatório.

Todos os entrevistados se posicionaram como defensores da natureza e demonstraram interesse em contribuir para a conservação dos recursos naturais daquela região.

Apesar da consciência demonstrada pelos pescadores, o cenário visualizado na área da pesquisa sinaliza para a necessidade de haver mudança de comportamento por parte dos frequentadores daquela área do reservatório, em benefício da conservação do meio ambiente, especialmente dos recursos hídricos.

Zulauf (2000) chama a atenção sobre as questões ambientais de maneira enfática e contundente, quando argumenta que o caminho que a humanidade está percorrendo pode levála a uma rota de colisão com a quantidade de resíduos gerados.

[...] Existem condições tecnológicas e uma razoável consciência coletiva da necessidade de aplicação dessas técnicas, mediante planos, programas e projetos para desviar o caminho da humanidade da rota de colisão com o entulho gerado pela irresponsabilidade coletiva de raízes históricas e culturais dessa mesma humanidade. (ZULAUF, 2000, p. 100) 
O autor ainda critica a ineficácia e a lentidão das ações fiscalizatórias/punitivas dos órgãos públicos responsáveis pelas ações de proteção ao meio ambiente, no sentido de adotar as medidas necessárias para reverter a situação em que se encontra a degradação do meio ambiente. Ressalta-se que, via de regra, tais ações costumam ficar emperradas por uma burocracia que retarda a aplicação dos planejamentos e, consequentemente, os seus resultados:

A angústia dos estudiosos desses problemas relaciona-se à lentidão das decisões político-administrativas destinadas a estimular as práticas de mecanismos de reversão da síndrome do colapso ambiental. A velocidade de reação e as decisões desencadeadoras dos processos corretivos e preventivos não acompanham o galope da depredação da base de sustentação da vida provocada por comportamentos coletivos inconsequentes (ZULAUF, 2000, p. 100).

O citado autor destaca, ainda, a importância do papel da mídia quanto à divulgação do processo de consciência ambiental:

[...] há que se investir com criatividade no processo de tomada de consciência, mediante forte dramatização, atraindo a atenção da mídia, para reafirmar o que já foi exaustivamente denunciado, e mais, para destacar o insubstituível papel da mídia na formação da vontade social. Quanto mais for possível acelerar o processo de transformação comportamental com relação ao meio ambiente, menor será o lamento, quando vierem a ocorrer as catástrofes engatilhadas, por não terem sido evitadas a tempo (ZULAUF, 2000, p. 100).

Nunes (2014a) chama a atenção para a necessidade de cientistas, pesquisadores e organizações não governamentais se disporem a discutir e propor alternativas capazes de promover medidas de controle da destruição da natureza, que se depara nos dias atuais:

[...] Destinar corretamente os resíduos domésticos [...] e a prática de medidas simples que estabeleçam a cultura da sustentabilidade em cada família. [...] reduzindo-se os desperdícios, os despejos de esgoto doméstico nos rios [...] os danos causados ao meio ambiente serão drasticamente minimizados e a sustentabilidade dos assentamentos humanos e atividades econômicas de qualquer natureza estará assegurada (NUNES, 2014a, s/p).

A autora alerta para o fato de que as políticas de conservação do meio ambiente e sustentabilidade precisam ser consideradas, pelos governantes, como prioridade em qualquer projeto econômico. E salienta, ainda, a relevância da educação e do conhecimento dos cidadãos sobre suas ações perante o meio ambiente e suas consequências:

[...] o mais importante de tudo é educar e fazer com que o cidadão entenda que tudo o que ele faz ou fará gerará um impacto no meio ambiente que o cerca. E que só com práticas e ações que visem à sustentabilidade dessas práticas, estará garantindo uma vida melhor e mais satisfatória, para ela mesma e para as gerações futuras (NUNES, 2014a, s/p).

Em nome do desenvolvimento industrial, tecnológico e do crescimento das economias mundiais, as ações em busca do desenvolvimento sustentável se deparam com obstáculos ainda mais desafiadores.

Nunes (2014b) faz, também, um questionamento sério ao afirmar que a irresponsabilidade humana pode levar a humanidade a um caminho sem volta, se não houver mudança de comportamento do homem na terra:

[...] Cedo ou tarde, os impactos desse modo de vida se tornarão irreversíveis e populações inteiras sentirão a mão pesada da natureza sobre suas vidas. [...] alterar as relações de consumo e educar a população para o real significado das políticas de 
conservação do meio ambiente pode ser a única forma de garantir a sustentabilidade ambiental. [...] entender que se os recursos do planeta não tiverem "a oportunidade" de renovarem-se e de sustentarem-se sob a pressão de uma demanda constante de consumo exacerbado, a vida no planeta [...] acabará de forma dramática e somente através desse processo de conscientização poderemos garantir a sustentabilidade ambiental (NUNES, 2014b, s/p).

O ser humano está acostumado a consumir, não raro, mais do que necessita para viver, a gerar resíduos em grande quantidade, desperdiçar grande parte daquilo que adquire, logicamente, destruir a natureza sem pensar muito nas consequências de tais comportamentos. A partir do conhecimento e da conscientização acerca dos problemas decorrentes do mau uso dos recursos naturais e suas consequências, acredita-se que a sociedade estará mais propensa a participar, de forma efetiva, de ações que gerem mudanças de comportamento, objetivando a busca pelo respeito e conservação do meio ambiente, contribuindo, dessa forma, para garantir a disponibilidade dos recursos naturais em quantidade e qualidade para as gerações presentes e futuras.

Rodrigues (1997 apud REIGOTA, 2007, p. 221) argumenta que "a sustentabilidade está centrada no exercício responsável da cidadania, com a distribuição equitativa da riqueza que gera. Não utiliza mais do que pode ser renovado e favorece condições dignas de vida para as gerações atuais e futuras".

Nessa perspectiva, o Relatório de Brundtland (1987 apud GONÇALVES, 2005), conceitua Desenvolvimento Sustentável como "[...] aquele que atende às necessidades do presente sem comprometer as possibilidades de as gerações futuras atenderem às suas próprias necessidades".

Apesar de importantes acordos já terem sido elaborados e aprovados por representantes de várias nações, preocupados com a questão ambiental, especialmente em conferências internacionais mediadas pela ONU, a realidade mostra que ainda há um espinhoso e longo caminho a ser percorrido em busca de alternativas que representem um avanço significativo para a humanidade e a qualidade de vida no planeta.

Nesse contexto, os autores pesquisados sinalizam para a necessidade de haver medidas de prevenção e conscientização que possam gerar mudanças de comportamento da sociedade, ante as questões envolvendo o meio ambiente, objetivando promover a educação e a consciência ecológica do cidadão.

\section{Considerações finais}

A análise dos questionários evidenciou que os pescadores possuem conhecimento sobre a legislação que regulamenta a pesca, porém, não a observa, o que aponta para a necessidade urgente de uma mudança de comportamento, que direcione as ações do homem para o uso sustentável dos recursos naturais.

A presença de pescadores nos tablados, durante o período da piracema, reforça a hipótese de urgência nas intervenções do Estado como órgão fiscalizador e do município e associação de pescadores como parceiros, para intervenções que resultem em mudanças de paradigmas sustentadas na educação ambiental, com foco específico voltado para a população de pescadores.

Os participantes da pesquisa conhecem, também, o cenário atual das mudanças climáticas que o planeta está enfrentando e a necessidade premente de implantação de medidas que minimizem os impactos ambientais causados pelo homem ao meio ambiente. 
No entanto, diante da situação visualizada na área delimitada para a pesquisa, considera-se que, quando se trata de uma mudança de comportamento e atitudes de caráter prático em busca da conservação dos recursos naturais, pouco se tem feito de concreto em benefício do ecossistema que compõe aquela área, apesar da consciência manifestada pelos participantes da pesquisa.

A necessidade de realização de atividades que promovam a mudança de comportamento via educação ambiental revela-se emergencial, tendo em vista que, apesar de todos os pescadores admitirem ter conhecimento sobre a gravidade dos problemas ambientais, bem como sobre a influência dos tablados em relação à poluição dos mananciais e à falta de conservação dos recursos naturais, mantêm-se reproduzindo atitudes de degradação ao meio ambiente.

A conscientização, o conhecimento da situação atual e a importância de se preservar a natureza precisam ser trabalhados, de forma eficaz, junto aos pescadores, uma vez que a legislação, por si só, não se traduz em resultados práticos.

O que pode gerar resultados concretos é a adequação da atividade pelo licenciamento ambiental, conforme exigências dos órgãos ambientais envolvidos (federal, estadual e municipal), prevendo o controle ambiental do uso dos recursos hídricos pelos próprios usuários.

Para se atingir essa meta, é imprescindível a criação de uma associação de pesca e lazer. O licenciamento ambiental dos tablados e o controle das atividades pelos próprios usuários poderão contribuir para a preservação dos recursos hídricos.

Foi observada a existência de cesto de lixo nos tablados, o que demonstra responsabilidade com o meio ambiente e preocupação em acondicionar e depositar os resíduos no local apropriado. Essas ações apontam para a possibilidade de sucesso de intervenções públicas no sentido de potencializar projetos de educação ambiental, como medida preventiva de proteção ao meio ambiente.

A pesquisa revela que a ação dos órgãos públicos na região se mostra incipiente, o que confirma que a existência de leis não garante resultados efetivos e não apresenta nenhum impacto positivo na preservação ambiental da região.

Faz-se necessária a continuidade mais aprofundada desta pesquisa, com a ampliação do período de monitoramento para garantir a confiabilidade das ações de preservação naquele ecossistema.

Após a aplicação e análise do questionário, foi proposto um folder direcionado ao público alvo da pesquisa, contendo informações sobre a piracema, a legislação que regulamenta a atividade pesqueira e dicas de como proteger os recursos naturais, especialmente os recursos hídricos.

O folder foi distribuído entre os participantes da pesquisa e outros pescadores que se encontravam no local no dia da última visita e, também, enviado às prefeituras municipais como contribuição para possíveis ações de intervenção do poder público naquela região, com políticas públicas de preservação da biota local.

A partir dos resultados obtidos neste trabalho, os pesquisadores evidenciam o interesse em propor estudos mais aprofundados que possam contribuir para a criação de linhas de pesquisa e desenvolvimento de projetos relacionados à preservação ambiental, especialmente dos recursos hídricos.

\section{Referências}


BRASIL. Lei Federal n. 9.605, de 12 de fevereiro de 1998. Dispõe sobre as sanções penais e administrativas derivadas de condutas e atividades lesivas ao meio ambiente, e dá outras providências. Brasília: Casa Civil, 1998. Disponível em: <http://www.planalto.gov.br/ccivil_03/leis/19605.htm>. Acesso em: 16 maio 2014.

BRASIL. Lei n. 11.959, de 29 de junho de 2009. Dispõe sobre a Política Nacional de Desenvolvimento Sustentável da Aquicultura e da Pesca, [...] e dá outras providências. Brasília: Casa Civil, 2009. Disponível em: <http://www.planalto.gov.br/ccivil_03/_ato20072010/2009/Lei/L11959.htm>. Acesso em: 29 mar. 2014.

CARVALHO, I. C. M. Educação ambiental: a formação do sujeito ecológico. 5. ed. São Paulo: Cortez, 2011.

COMPANHIA ENERGÉTICA DE MINAS GERAIS - CEMIG. Disponível em: $<$ http://www.cemig.com.br/pt-br/a_cemig/Nossa_Historia/Paginas/2005.aspx>. Acesso em: 02 fev. 2015.

CONSELHO NACIONAL DE MEIO AMBIENTE - CONAMA. Resolução n. 302/02, de 20 de março de 2002. Brasília: MMA/CONAMA, 2002. Disponível em: <http://www.mma.gov.br/port/conama/res/res02/res30202.html >. Acesso em: 16 maio 2014.

CONSELHO NACIONAL DE MEIO AMBIENTE - CONAMA. Resolução n. 357/05, de 17 de março de 2005. Brasília: MMA/CONAMA, 2005. Disponível em: <http://www.mma.gov.br/port/conama/res/res05/res35705.pdf>. Acesso em: 16 maio 2014.

DAMO, Andreisa; MOURA, Danieli Veleda; CRUZ, Ricardo Gautério. Conscientização em Paulo Freire: consciência, transformação e liberdade. Contribuciones a las Ciencias Sociales, Málaga, s/v, s/n, s/p, Enero 2011. Disponível em: <www.eumed.net/rev/cccss/11>. Acesso em: 03 fev. 2015.

GONÇALVES, D. B. Desenvolvimento sustentável: o desafio da presente geração. Revista Espaço Acadêmico, Maringá, ano 5, n. 51, s/p, ago. 2005. Disponível em: <http://www.espacoacademico.com.br/051/51goncalves.htm>. Acesso em: 28 jul. 2014.

GUERRA, Isabel Carvalho. Pesquisa qualitativa e análise de conteúdo: sentidos e formas de uso. 1. ed. São João do Estoril (Portugal): Princípia, 2006.

MATO GROSSO DO SUL [Estado]. Decreto n. 1.210, de 03 de julho de 2012. Dispõe sobre a instalação de tablados flutuantes nos corpos hídricos do estado de Mato Grosso e dá outras providências. Diário Oficial do Estado do Mato Grosso do Sul, Cuiabá, 3 jul. 2012. Disponível em: <http://www.legisweb.com.br/legislacao/?id=242971>. Acesso em: 25 jul. 2014.

MINAS GERAIS. Secretaria de Estado de Meio Ambiente e Desenvolvimento Sustentável. Portaria $n^{o} 156$, de 13 de outubro de 2011. Dispõe sobre a regulamentação da pesca nas Bacias Hidrográficas dos Rios Grande e Paranaíba, no Estado de Minas Gerais, no período de piracema e dá outras providências. Belo Horizonte: SEMADS, 2011. Disponível em: 
<www.ief.mg.gov.br/images/stories/pesca/piracema/portaria_n_156.pdf>. Acesso em: 5 jul. 2014.

MINAYO, M. C. (Org.). Pesquisa social: teoria, método e criatividade. 18 ed. Petrópolis : Vozes, 2001. (Temas Sociais).

MOUSINHO, P. Glossário. In: TRIGUEIRO, André. (Coord.) Meio ambiente no século 21. Rio de Janeiro : Sextante, 2003. p. 333-368.

NUNES, R. O meio ambiente e a sustentabilidade. In: Homepage Ecologia urbana: o caminho para uma sociedade sustentável. Disponível em: <http://www.ecologiaurbana.com.br/conscientizacao/meio-ambiente-sustentabilidade>. Acesso em: 07 ago. 2014a.

. Como garantir a sustentabilidade ambiental? In: Homepage Ecologia urbana: o caminho para uma sociedade sustentável. Disponível em: <http://www.ecologiaurbana.com.br/sustentabilidade/como-garantir-sustentabilidadeambiental>. Acesso em 07 ago. 2014b.

REIGOTA, M. A. S. Ciência e sustentabilidade: a contribuição da educação ambiental. Avaliação. Revista de Avaliação da Educação Superior, Campinas, v. 12, n. 2, p. 219-232, Jun. 2007.

SILVA, L. M. C. Gestão Sustentável de Reservatórios. In: THEODORO, S. H. (Org.). Conflitos e uso sustentável dos recursos naturais. Rio de Janeiro: Garamond Universitária, 2009. p. 29-51.

TUNDISI, J. G. A água e os sistemas de sustentação à vida. In: século XXI: enfrentando a escassez. São Carlos: RIMA, 2009. p. 1-4. (Org.). Água no

VASCONCELOS, M. G. Avaliação integrada da qualidade da água do Rio Uberabinha MG, com base na caracterização química dos sedimentos e de espécimes da Ictiofauna. 2012. 188 f. Tese (Doutorado em Química) - Universidade Federal de Uberlândia, Uberlândia, 2012.

ZULAUF, W. E. O meio ambiente e o futuro. Estudos Avançados, São Paulo, v. 14, n. 39, p. 85-100, Maio/Ago. 2000. Disponível em: <http://dx.doi.org/10.1590/S010340142000000200009>. Acesso em: 7 ago. 2014. 